\title{
Sound Localization Strategies in Three Predators
}

\author{
Catherine E. Carr $^{\text {a }}$ Jakob Christensen-Dalsgaard ${ }^{\text {b }}$ \\ ${ }^{a}$ Department of Biology, University of Maryland Center for the Comparative and Evolutionary Biology of Hearing, \\ College Park, Md., USA; ${ }^{b}$ Institute of Biology, University of Southern Denmark, Odense, Denmark
}

\section{Key Words}

Alligator · Auditory systems · Barn owl · Lizard · Neural coding

\begin{abstract}
In this paper, we compare some of the neural strategies for sound localization and encoding interaural time differences (ITDs) in three predatory species of Reptilia, alligators, barn owls and geckos. Birds and crocodilians are sister groups among the extant archosaurs, while geckos are lepidosaurs. Despite the similar organization of their auditory systems, archosaurs and lizards use different strategies for encoding the ITDs that underlie localization of sound in azimuth. Barn owls encode ITD information using a place map, which is composed of neurons serving as labeled lines tuned for preferred spatial locations, while geckos may use a meter strategy or population code composed of broadly sensitive neurons that represent ITD via changes in the firing rate.
\end{abstract}

(C) 2015 S. Karger AG, Basel

\section{Introduction}

The interaction between predators and prey produces strong selection pressures for both protagonists. This interaction is often called an 'arms race', for example between bats and moths, but this is imprecise because the race is asymmetrical - a losing predator might find other prey items, but a losing prey is out of the race. Nevertheless, the evolution of measures and countermeasures is assumed to sharpen the performance of both organisms. Both predators and prey benefit from accuracy and speed of sensory processing and should also coordinate inputs from different sensory systems. However, accuracy and integration on one hand, and speed on the other, are to some extent complementary, and this, together with the cost of neural tissue and processing in general, can be expected to constrain performance [Laughlin, 2001]. These features of sensory coding will be discussed, using sound source localization as an example, where localization can be combined with vision or other senses to direct prey capture.

In this review, we will focus on some of the neural strategies for sound localization and encoding interaural time differences (ITDs) in three predatory species. We review recent work on barn owls, alligators and the Tokay gecko. All are Reptilia [Modesto and Anderson, 2004]; birds and crocodilians are sister groups among the extant archosaurs, while geckos are lepidosaurs. It is not clear whether or not these reptiles and birds share a common ancestor with a tympanic middle ear [Clack, 2011; Christensen-Dalsgaard and Manley, 2013]. Nevertheless, their central auditory pathways are very similar, suggesting their common ancestors may have been rudimentarily sensitive to airborne sound through bone con-

\section{KARGER 125}

(c) 2015 S. Karger AG, Base

0006-8977/15/0861-0017\$39.50/0

E-Mail karger@karger.com

www.karger.com/bbe
Catherine E. Carr

Department of Biology, University of Maryland

Biology-Psychology Building

College Park, MD 20742 (USA)

E-Mail cecarr@umd.edu 
duction [Lombard and Sumida, 1992; Christensen et al., 2015]. Despite the similar organization of their auditory systems, we will show that archosaurs and lizards use different strategies for encoding ITDs that underlie localization of sound in azimuth.

\section{Predation and Localization Cues}

Sound localization plays a key role in predation in many vertebrates, since predators can detect and localize prey from the sounds they produce. The comparison of the signal arrival time (onset, ongoing phase and transients) and amplitude spectra at the two ears provides the basis for sound source localization, with these cues lumped as ITDs and interaural level differences (ILD), respectively. Use of time and level differences depends on sound frequency and head size. ILD cues improve when the wavelength of the sound is smaller than the dimensions of the animal's head, so that sufficient sound shadowing occurs to produce amplitude differences of the signal at the two ears, while ITDs are best in a window from a few 100 to a few $1,000 \mathrm{~Hz}$. Thus, the choice of cues can depend on both head size and frequency.

Many predators are good at sound source localization, measured as the minimum resolvable angle or threshold ability to distinguish between sound sources separated in azimuth [Heffner and Heffner, 1992]. We focus on barn owl localization behavior, since there are no psychophysical measures from alligators and lizards, although there are observations of localization behavior in each group [Sakaluk and Belwood, 1984; Bierman and Carr, 2015]. Minimum resolvable angles have been studied in a number of bird species, with thresholds ranging from $2-3^{\circ}$ in the barn owl, saw-whet owl and marsh hawk to over $100^{\circ}$ in the zebra finch [Rice, 1982; Bala and Takahashi, 2000; Klump, 2000; Bala et al., 2003]. It is not surprising that the smallest minimum resolvable angles have been measured in raptors. The barn owl, for example, is a nocturnal predator that depends largely on hearing to find prey, and has developed exceptional sound localization abilities. These owls can hunt in total darkness, provided the space is familiar to them, but generally they combine visual and auditory cues. They are efficient predators; an adult feeding a nest of owlets was observed bringing in 50 mice a night [Bunn et al., 1982].

Barn owls also hear higher-frequency sounds than most birds, with sensitivity up to $12 \mathrm{kHz}$ [Konishi, 1973]. It has been argued that a unique adaptation underlies this increased sensitivity, the asymmetrical positions of owl right and left ear flaps. The asymmetric ear flaps create ILDs that vary with elevation, allowing owls to use a bicoordinate system for sound localization, where ITDs mediate horizontal sound localization and ILDs mediate sensitivity to elevation. ILDs become more salient at higher frequencies, because of head shadowing, and the pairing of ITDs and ILDs should increase selection for high-frequency hearing [Volman, 1990; Volman and Konishi, 1990]. In addition, the barn owl's facial ruff enhances elevation-dependent changes in signal intensity. Vertical sound localization thresholds are about two times poorer for changes in elevation than azimuth, and resolution is generally best for broadband signals [von Campenhausen and Wagner, 2006]. Pairing ILDs and ITDs could enhance selection for processing ITDs at high frequencies, and barn owls are sensitive to ITDs in sounds of up to 8 or $9 \mathrm{kHz}$, unlike most birds and mammals, which are generally only able to detect ITDs in sounds of up to about $2 \mathrm{kHz}$ [Grothe et al., 2010]. The envelopes of amplitude-modulated signals may provide ITD information for high-frequency sounds [Joris and Yin, 1995].

\section{Maps and Meters and the Evolution of Sound Localization}

Analyses of ITD coding strategies are especially interesting because of the opportunity they provide to test structure-function hypotheses in the brain. Neural populations can encode information as 'maps', composed of neurons serving as labeled lines tuned for preferred spatial locations, or 'meters', in which broadly sensitive neurons represent information via their firing rates (fig. 1) [Lee and Groh, 2014]. For the meter scheme, also called a 'slope code', populations of neurons on each side of the brain change their firing rate with stimulus location, and comparison of the two populations can be used to decode stimulus ITD. This population code makes no explicit predictions about the organization or structure of the circuit. For the map-coding strategy, arrays of neurons are tuned to different ITDs. Individual neurons have different best ITDs, and all locations are represented in a labeled line or place code (fig. 1). Labeled lines are well suited to encode continuous variables like ITDs and should be visible as an array in the brain. Arrays are not absolutely required, since ordered delays could emerge from a number of different mechanisms, but both developmental constraints and parsimony predict formation of map-like arrays.

Interestingly enough, the meter -and map-coding strategies may reflect evolutionary history as much as op-
18

Brain Behav Evol 2015;86:17-27 DOI: $10.1159 / 000435946$
Carr/Christensen-Dalsgaard 


\section{$\operatorname{s.MM} \cdot X$}

Fig. 1. Map- versus meter-coding strategies. a Place code, where tuning curves for best ITDs are homogenously distributed over the physiological range of ITDs, exemplified by the barn owl NL. b Population code, where two populations of neurons with broad tuning curves can encode change in ITD through changes in firing rate, exemplified by the lizard auditory nerve. In the population code, the peaks of the tuning curves may lie outside the physiological range.

timal coding. Meters and maps have been found in mammals and archosaurs, respectively [Grothe et al., 2004; Schnupp and Carr, 2009; Grothe et al., 2010]. Sensitive, high-frequency hearing of airborne sound appears to be a fairly recent event in vertebrate evolution, with the major tetrapod radiations evolving tympanic hearing in parallel [Christensen-Dalsgaard and Carr, 2008; Clack, 2011; Grothe and Pecka, 2014]. Grothe and Pecka [2014] have proposed that small mammals evolved tympanic hearing under different constraints than the reptiles and amphibians. Frogs and reptiles have a single middle ear bone, the columella, whose mass and mechanics favor low-frequency conduction [Manley, 2010]. Mammals have three middle ear bones that could favor higher-frequency sound conduction. These differences, plus a scenario where early mammals were small and possibly nocturnal, might, therefore, provide different selective strategies for the evolution of sound localization circuits in modern mammals and archosaurs [Manley, 2012; ChristensenDalsgaard and Manley, 2013]. However, three middle ear bones are not essential for high-frequency hearing, which has also appeared among the reptiles, notably the pygopod geckos [Manley and Kraus, 2010].

It should also be noted that neither coding scheme is monolithic. Archosaurs have access to the same high level of information present in the 'slope' of the tuning curve as do mammals [Takahashi et al., 2003] and thus should be able to use both coding strategies. In this 'best of both worlds' scenario, the peak firing rate encodes stimulus location in azimuth, while information from the slope is sufficient to explain the owl's high behavioral acuity. Both coding strategies work; some birds and mammals localize sound very precisely, resolving ITDs of as low as $10-20 \mu$ s

Sound Localization Strategies
[Shackleton et al., 2003; Takahashi et al., 2003; Butts and Goldman, 2006]. Finally, analyses of how well each decoding strategy works in more complex acoustical environments suggest that meters in their simple form may be insufficient to estimate sound direction that matches behavioral accuracy, with better estimates from more heterogeneously tuned neurons [Butts and Goldman, 2006; Goodman et al., 2013; Franken et al., 2015]. The variability in neuronal responses to sound location observed in the map-coding strategy may not only generate a space map that can readily interface with visual maps to guide orientation and prey-catching behavior, but also provide the accuracy observed at the behavior level. In the next sections of this review, we will examine neural processing of ITDs in two archosaurs, alligators and in the specialized barn owls.

\section{Sound Direction Maps: Neural Processing of Time Differences in Archosaurs (Birds and Alligators)}

Maps may represent the plesiomorphic condition in birds, since they have been described in chicken [Rubel et al., 1976; Parks and Rubel, 1978; Köppl and Carr, 2008] and emu [MacLeod et al., 2006]. Whether or not ITDs are mapped in alligators is an open question. Crocodilians and birds are sister groups, and share many common features, although crocodilians are sensitive to a narrower range of frequencies than birds, with best hearing between 300 and 2,000 Hz [Wever, 1978]. Extant crocodilians have excellent hearing in both air and water [Higgs et al., 2002; Bierman et al., 2014] and an extensive repertoire of calls [Vergne et al., 2009; Young et al., 2014]. They also appear to be able to localize sound [Beach, 1944; Dinets, 2013; Bierman et al., 2014]. It is presently unknown whether crocodilians follow the avian pattern, where maps of visual and auditory space are in register in the optic tectum, but it is likely, since multisensory alignment characterizes all tecta so far examined. No other animals display the precision of the barn owl's auditory map in the tectum, however, where both ITDs and ILDs contribute to spatially restricted receptive fields.

The relatively low-frequency crocodilian hearing range is relevant to discussion of map- versus meter-coding strategies. The response of the nucleus laminaris (NL) neurons has been described as a cross-correlation of narrow-band inputs from the ipsi- and contralateral ears [Batra and Yin, 2004; Fischer and Pena, 2009]. The accuracy of a place code decreases at low frequencies, however, because the ITD tuning curves broaden, so that even 
a large change in ITD leads to only a small change in the spike rate. Also, with low best frequency ITD functions, the response maxima often lie outside the physiological range of ITDs, so that the resolution of the place code of best ITDs decreases. Harper and McAlpine [2004] and Harper et al. [2014] proposed an optimized solution for low-frequency ITD coding would be to compare the response slopes of two populations of neurons, one in each hemifield, with response peaks outside the physiological range of ITD, i.e. the meters described above [Harper and McAlpine, 2004]. These authors further proposed different coding regimes would be optimal at different sound frequencies, i.e. a meter at low frequencies and maps at higher frequencies. These coding strategies would also depend on head size [Harper et al., 2014]. Given the lowfrequency hearing in crocodilians, their best coding strategy might be to compare two meters.

Nevertheless, the auditory brain stem structures and the response properties of brain stem neurons in birds and crocodilians are very similar, and parsimony would suggest that both use similar processing strategies for auditory processing [Carr et al., 2009]. The alligator NL encodes ITDs and receives phase-locked input from the cochlear nucleus magnocellularis (NM), as is also the case in birds. In the alligator NL, best ITDs are broadly distributed throughout the contralateral hemisphere, and preliminary data suggest that ITDs may be mapped in NL, since best ITDs close to $0 \mu$ s were measured in more medially located neurons, whereas contralateral best ITDs were found in more lateral regions of the NL [Carr et al., 2009]. The best ITDs of NL neurons in young alligators often lie outside the apparent physiological range, however [Bierman et al., 2014]. There are, therefore, several factors to consider when predicting ITD coding strategies, such as the real physiological range and the animal's life history.

\section{The Role of Coupled Ears in Alligator ITD Coding}

One unique feature of the archosaurs is that their ears are acoustically coupled by air-filled cranial cavities [Bierman et al., 2014]. This coupling generates increased directional cues and may modify the available ITDs. Such airfilled cavities or sinuses appear to have evolved independently in crocodilians and other archosaurs, including dinosaurs and their avian descendants [Dufeau, 2011, reviewed in Bierman and Carr, 2015]. Sound transmission through these sinuses would allow the eardrums of alligators to act to some degree like pressure difference receivers.
CT-based material has revealed the extent of the paratympanic sinuses that couple the middle ears [Witmer and Ridgely, 2009; Bierman et al., 2014]. These connections lighten the skull in addition to coupling the ears, and appear to have evolved multiple times among the archosaurs [Dufeau, 2011]. In birds, the ventral interaural pathway, or interaural canal, is most prominent [Calford and Piddington, 1988], since dorsal connections are via trabeculated bone. In alligators, both pathways are well developed, and it has been proposed that the dorsal pathway further couples the middle ear cavities and could amplify the directionality afforded by the ventral interaural pathway [Kundrát and Janáček, 2007; Bierman et al., 2014]. The effects of coupling are frequency dependent, but at low frequencies, coupled middle ears can increase the physiological range of ITDs by a factor of about 3 in birds and in simulations [Hyson et al., 1994; Köppl and Carr, 2008; Michelsen and Larsen, 2008; Vossen et al., 2010; Bierman et al., 2014]. Laser vibrometry measurements in alligators also show that the interaction of the internal and external sounds at the eardrum leads to increased directionality of eardrum vibrations [Bierman et al., 2014]. Auditory brain stem response data have shown that eardrum directionality leads to directional responses even at the level of wave 1 of the auditory brain stem response, most likely the compound action potential of the auditory nerve [Bierman et al., 2014].

The increased directionality of the coupled ears leads to an effectively larger head and larger range of ITDs. The relative advantages of map- versus meter-coding strategies depend both upon head size and frequency range, and there may be selection for different representations at different sound frequencies [Harper and McAlpine, 2004; Harper et al., 2014]. Data from the alligator support a map code, because recording sites with best ITDs near $0 \mu$ s tended to be medial in NL and best ITDs of $600 \mu$ s or greater were found lateral in NL. Furthermore, best ITDs appeared to be distributed evenly throughout the recorded range (fig. 2c). The range of recorded best ITDs was very large in the 2- to 3-year-old alligators examined in the study by Carr et al. [2009], ranging from $100 \mu$ s ipsilateral ear leading to $1,200 \mu$ s contralateral leading, with median values of about $450 \mu \mathrm{s}$, as compared to median values of about $90 \mu$ s in chicken [Köppl and Carr, 2008] and $173 \mu$ s in the gerbil [Pecka et al., 2008]. These alligators had ears that were about $3 \mathrm{~cm}$ apart; so many peaks of the ITD tuning curves should fall outside even the extended physiological range created through coupling of the ears. Crocodilian head size increases throughout life to a head width of nearly $30 \mathrm{~cm}$ in adult alligators [Wood- 

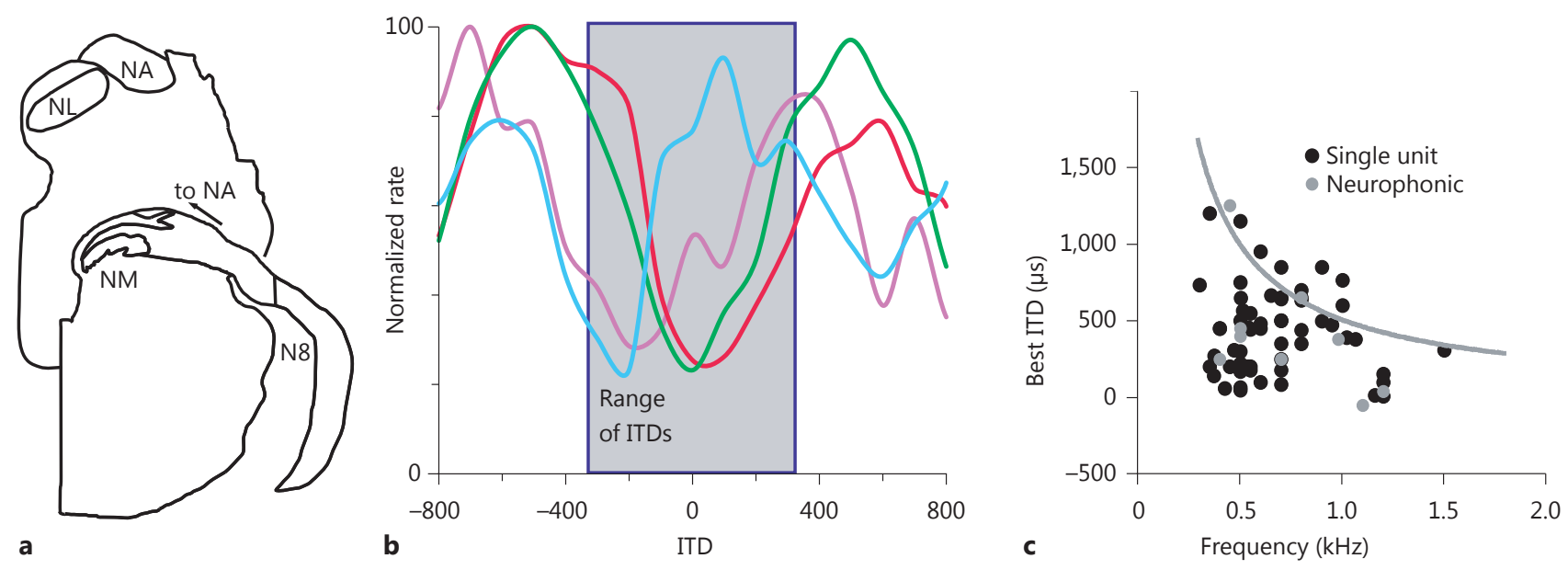

Fig. 2. ITD coding within alligator NL. a Schematic cross sections through the alligator brain stem at the level of the 8th nerve, showing the cochlear NM and the ascending nerve root to the cochlear nucleus angularis (NA). b Interaural delay curves plot the response of NL neurons against changing ITDs in the alligator. Five singleunit recordings were selected from left-hand NL recordings to display a range of different best ITDs in the contralateral hemifield, i.e. positive ITDs. One had a peak within the physiological range

ward et al., 1995]. If the ITD map does not change throughout life, larger animals may experience peak responses from NL neurons with best ITDs in far contralateral space, while smaller animals should only encounter slope responses. Both cases should allow alligators to discriminate small changes in the location of sound sources, although further study is needed to evaluate which strategies are used.

\section{Specialization of the Archosaur Model - Time Differences, the Jeffress Model and Place Codes in Barn Owls}

Konishi and his colleagues found that barn owls make accurate head saccades towards a sound, which will bring the source directly in front of the bird [Knudsen et al., 1979]. Later studies measured the habituation and recovery of the pupillary dilation response to relevant sounds [Bala and Takahashi, 2000]. This task excludes the accuracy of the listener's motor behavior from the localization measure and provides minimum audible angle estimates of about $3^{\circ}$ for broadband noise. In frontal space, these minimum audible angles correspond to ITDs of about 2.5 of ITDs (blue line); three were outside. c Best ITDs were distributed throughout the contralateral hemifield. Like all animals described so far, best ITDs showed less scatter with increasing best frequency for all single units (black circles) and neurophonic recordings (gray circles). The gray line follows ITD values corresponding to 0.5 cycle, the 'pi-limit'. b, c Data modified from Carr et al. [2009].

$\mu$ s per degree [von Campenhausen and Wagner, 2006], or an ability to detect ITDs of about $7.5 \mu$ s. Localization of frontal targets is also most accurate [Bala et al., 2003; Wagner et al., 2013], presumably correlated with an expanded representation of the frontal binocular space in the optic tectum [Knudsen, 1982].

This behavioral acuity emerges in specialized brain stem circuits, beginning with precise encoding of stimulus phase in the auditory periphery [Köppl, 1997]. The auditory system uses phase-locked spikes to encode the timing of the auditory stimulus. Phase locking underlies accurate detection of temporal information, including ITDs, and is conspicuous in the barn owl. Owl auditory nerve fibers phase lock to acoustic stimuli up to $9 \mathrm{kHz}$, as opposed to about $2 \mathrm{kHz}$ in the pigeon, about $4 \mathrm{kHz}$ in the starling and 5-6 kHz in the blackbird and cat [Joris et al., 1994; Köppl, 1997]. The auditory nerve forms large specialized end-bulb synapses onto NM cell bodies, preserving the temporal relationship between nerve and postsynaptic neuron [Carr and Soares, 2002]. Precise temporal information is conveyed from NM to NL, where ITDs are first computed. Magnocellular axons project into NL, acting as delay lines to create maps of ITD, and their target neurons act as coincidence detectors to encode interaural 
phase difference. These delays are often asymmetrical, leading to neurons with best sensitivity in the contralateral hemifield [Pecka et al., 2008; Carr et al., 2009; Grothe et al., 2010; Bremen and Joris, 2013; Myoga et al., 2014].

The magnocellularis-laminaris circuit conforms to the predictions of the Jeffress model, which posits that individual neurons fire in response to precisely synchronized excitation from both ears and that systematically varying axonal conduction delays along the length of the nucleus serve to offset ITDs, so that each neuron is 'tuned' to a best ITD value equal to the signal delays from the left and right ear [Ashida and Carr, 2011]. This scheme turns systematic variations in ITDs into a topographic map of sound source location or place map [Carr and Konishi, 1990; Overholt et al., 1992; Köppl and Carr, 2008]. The anatomical arrangement of magnocellular inputs via the delay lines creates a topographic map of neurons with different preferred ITDs. Hence, the place of maximal activity within this map corresponds to a particular azimuthal location. The place map in the NL is preserved at higher stations of the auditory system and, at least in barn owls, is eventually aligned with the visual space map in the auditory midbrain and the optic tectum [Knudsen, 2002; Wagner et al., 2013].

\section{Maps of ITD}

There are two notable specializations in the brain stem circuit that barn owls use to compute and map ITDs. First, NM and NL are much larger than would be expected from owl brain size [Kubke et al., 2004]. Second, the map of ITD is transformed from the plesiomorphic condition, as observed in chicken [Rubel et al., 1976; Parks and Rubel, 1978; Köppl and Carr, 2008] and emu [MacLeod et al., 2006] where NL is a compact, often monolayer group of bitufted neurons organized into a topographic lamina map of ITDs. The plesiomorphic map is organized such that ITDs corresponding to frontal locations are mapped medially in NL, while peripheral ITDs are mapped laterally [Köppl and Carr, 2008]. The maps are created by NM projections to NL that act as delay lines [Carr and Konishi, 1988, 1990; Overholt et al., 1992; Seidl et al., 2014], with conduction delays similar to the range of ITDs available to each bird [Moiseff, 1989; Hyson et al., 1994; Köppl and Carr, 2008]. Evidence for delay lines is good in the chicken and emu, which show systematic shifts in conduction time of contralateral NM afferents in vitro [Overholt et al., 1992; MacLeod et al., 2006; Görlich et al., 2010; Seidl et al., 2014] and in vivo [Köppl and Carr,
2008]. Only the contralateral axons act as delay lines and are sufficient to create maps of ITD [Köppl and Carr, 2008; McColgan et al., 2014].

In barn owls, NL is not a monolayer, but is expanded dorsoventrally [Kubke and Carr, 2006]. The principal ITD axis is no longer mediolateral within an isofrequency slab, but dorsoventral, such that NL contains multiple maps of ITD that run from dorsal to ventral instead of one mediolateral map (fig. 3a). Both ipsi- and contralateral axons act as delay lines. Ipsilateral response phases increase and contralateral response phases decrease when an electrode is advanced from dorsal to ventral in NL [Carr and Konishi, 1988]. The array of interdigitating axons from each cochlear nucleus forms many parallel maps of ITD within each isofrequency band; these maps are not identical, but rather divide up the biological range of ITDs such that the medial NL contains maps of frontal ITDs, with $30^{\circ}$ on either side of the midline, with the midline designated as 0 - $\mu$ s ITD (fig. 3b). The range of ITDs mapped shifts smoothly and systematically towards contralateral ITDs towards lateral regions of NL. Frontal space $\left(0^{\circ}\right.$ or 0 - $\mu$ ITD) is represented throughout NL, and thus overrepresented with respect to the periphery [Carr et al., 2015]. These multiple, overlapping maps of ITD converge upon a single representation in the core of the central nucleus of the inferior colliculus.

In the first stage of ITD processing in NL, there are potential ambiguities between the response in NL and the actual ITD in auditory space, since the NL coincidence detectors respond to interaural phase differences and, therefore, generate peaks at multiple ITDs. The second stage of processing takes place in the core of the central nucleus of the inferior colliculus, where the multiple ITD maps in NL converge [Takahashi et al., 1987; Takahashi and Konishi, 1988] and the true ITD is computed by aligning interaural phase difference peaks across frequencies. The core is best described as a matrix in which preferred interaural phase difference and frequency co-vary, so that a single ITD activates all constituent neurons throughout the tonotopic axis [Wagner et al., 1987]. Thus, an ITD is conserved in a population of neurons at this stage, not in any single cell. Each array projects to ITD- and ILD-sensitive neurons in the contralateral lateral shell. These, in turn, project to space-specific neurons in the contralateral external nucleus of the inferior colliculus for the third stage of ITD processing. This third stage uses across-frequency integration to filter out phaseambiguous side peaks, forming neurons that respond mainly to the true ITD, endowing the space-specific neuron with ITD selectivity and azimuth coding. 


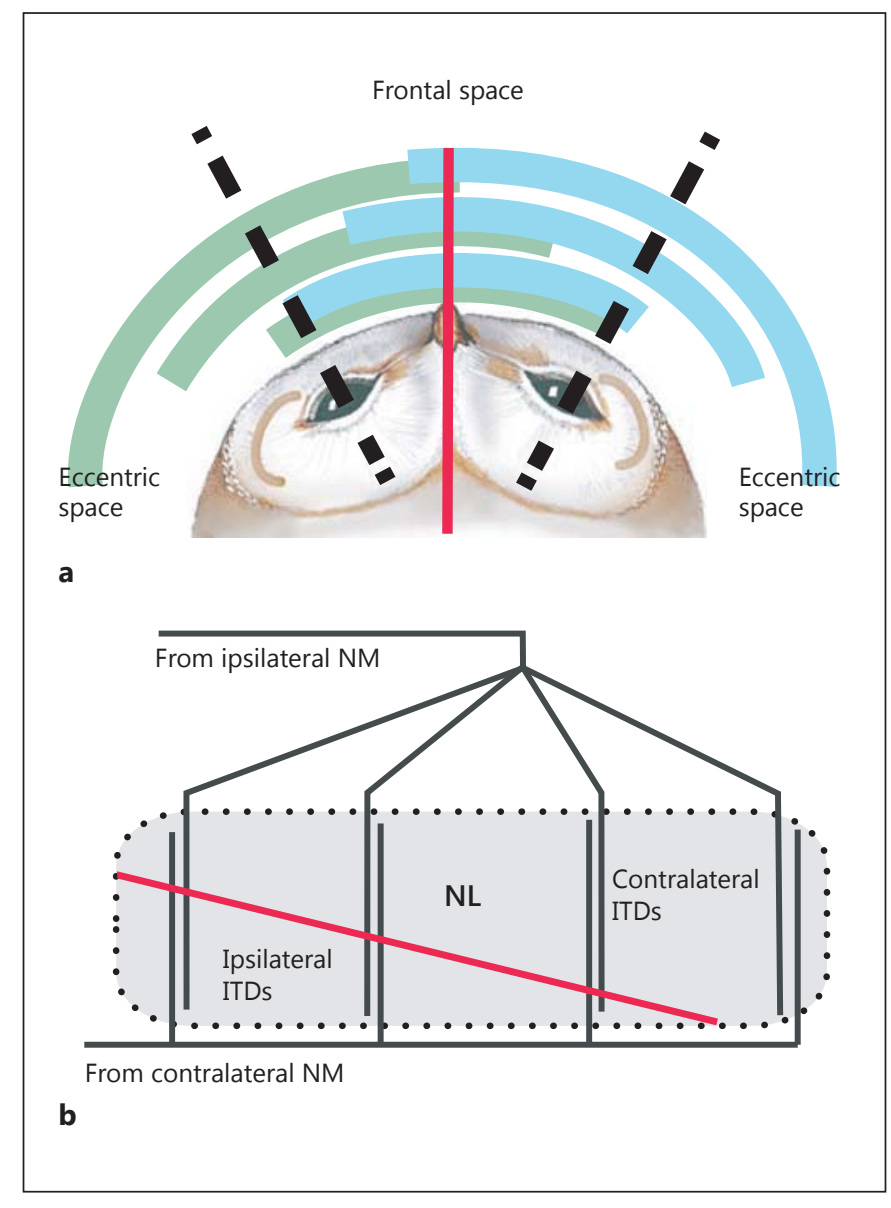

Fig. 3. Maps of ITD in the barn owl. a Frontal space is represented in both NLs, to create an overlapping representation of the approximately $30^{\circ}$ region on either side of the midline (red line, marks $0-\mu$ s ITD), schematized by the overlapping arcs between dashed black lines. $\mathbf{b}$ The range of ITDs mapped in NL shifts, so that frontal space is mapped throughout NL. In medial NL, more frontal space is mapped, so medial NL on both sides contains maps of both ipsilateral and contralateral ITDs (arcs closest to the owl), while more and more contralateral space is mapped in the central and lateral NL. The range of ITDs mapped in lateral NL regions encompasses the most eccentric space.

\section{Putting It All Together - Maps of Auditory Space}

The space-specific neurons in the external nucleus respond to sound only from a particular spatial locus. Each source is represented in the space map by a focus of activity in a population of neurons, and source displacement changes the pattern of activity in this population. Maps of auditory space are formed in the external nucleus of the inferior colliculus, and its targets in the optic tectum, but not in midbrain targets in the forebrain [Cohen and Knudsen, 1999]. Restricted lesions in the space map cause deficits in sound localization, showing that the map is important for localization behavior [Knudsen et al., 1993; Wagner, 1993]. However, a recovery from the behavioral deficit was observed, demonstrating that the adult auditory system has the capability of plasticity [Wagner, 1993]. Localization was completely lost only when both space map and forebrain auditory areas were lesioned [Knudsen et al., 1993].

The space map projects topographically to the optic tectum, where maps of visual and auditory space are in register. Tectal activity can direct the rapid head movements made by barn owls to auditory and visual stimuli [du Lac and Knudsen, 1990]. The tectum or superior colliculus plays a central role in multimodal and sensorimotor integration, and in gaze control in all vertebrates examined. Recent studies in chickens and owls show these circuits also function in spatial attention, interacting with forebrain structures to select stimuli for gaze and spatial attention [Knudsen, 2011]. The midbrain network, containing the optic tectum and isthmic nuclei, appears to play a role in evaluating the relative priorities of competing stimuli, then encodes them in a topographic map of space, much like the primate frontoparietal network [Mysore and Knudsen, 2011; Sridharan et al., 2014].

\section{Sound Localization Meters - Directional Hearing in Mammals and Lizards}

\section{Mammals}

Tympanic hearing in mammals is yet another 'experiment in hearing', with the novel origin of a tympanic ear [Manley, 2010, 2012; Christensen-Dalsgaard and Manley, 2013; Grothe and Pecka, 2014]. The mammalian middle ear originated through coupling of the middle ear bone to two other bones, first contacting the jaw through Meckel's cartilage and later freed and evolving into a tympanic ear. Unlike the ear of the other tetrapods, this middle ear was not located at the spiracles and probably not connected to the other ear via air spaces. The three-ossicle ear later gave mammals a unique opportunity to adapt hearing to higher frequencies, which had the advantage for sound localization that even small heads could produce a reliable sound shadow with more than a 15-dB difference between ipsi- and contralateral angles [Heffner and Heffner, 1992]. The emergence of an external ear in mammals amplified these directional ILD cues and would be useful for hearing in elevation, especially at high frequencies. For low frequencies, however, the sound shadowing cues are minimal and therefore arrival time cues are most salient. 


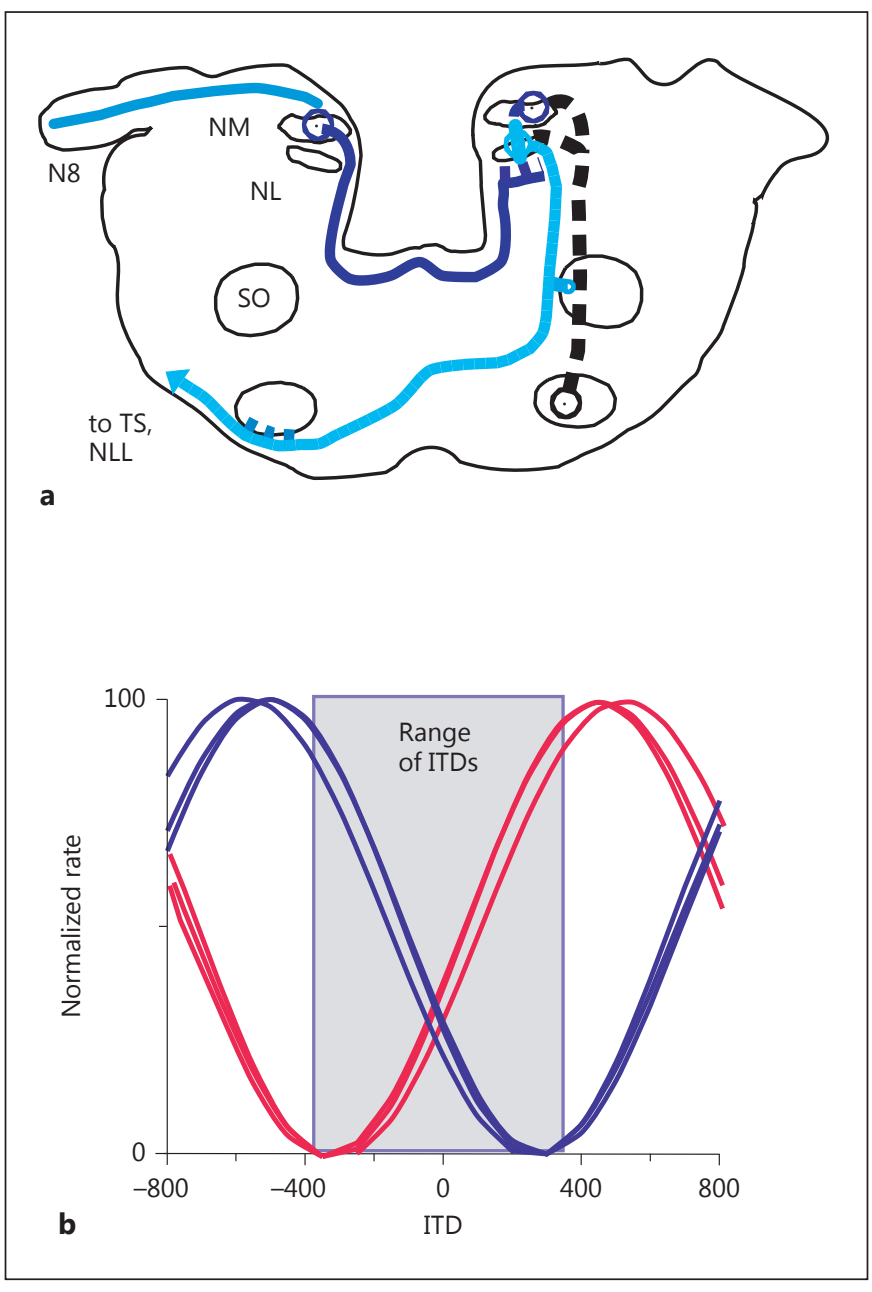

Fig. 4. Meter coding within the lizard auditory nerve. a Schematic cross section through the gecko brain stem at the level of the 8th nerve (N8), showing the cochlear NM and its bilateral projections to the NL. NL neurons project to the olivary nuclei and to the midbrain torus (blue line). Descending connections from the ventral superior olive (SO) are shown in black. Ascending connections to the nuclei of the lateral lemniscus (NLL) and torus semicircularis (TS) in light blue. Modified from Tang et al. [2012]. b Interaural delay curves plot the response of gecko auditory nerve fibers against changing ITDs. Three single-unit recordings were selected from right-hand auditory nerve recordings (red), then reflected to represent a similar pair from the left auditory nerve (blue). Generally, peaks were not within the physiological range of ITDs unless their best frequencies were above $2 \mathrm{kHz}$, i.e. a half cycle away from the ITD minimum created by the coupled ears. This minimum was about $240 \mu$ s [Christensen-Dalsgaard et al., 2011].

Strategies for processing sound localization cues in mammals have been controversial. It is clear that time and level cues are segregated in the CNS, but the processing of time cues has been debated over the last decade.
The earlier contention was that mammals possessed a Jeffress-like system leading to a map of ITDs like in birds. However, it has been shown that small mammals, specifically gerbils, do not map the ITDs that they encounter in life (restricted to $\pm 100 \mu$ s because of the small head size). Rather, the peaks of the ITD-sensitive responses are typically outside this physiological range. Therefore, it is more likely that the ITD-sensitive cells function like meters, where different ITDs are represented by different firing rates in the cells [McAlpine et al., 2001; Grothe et al., 2010]. This leads to effective lateralization, but not to any map of ITD. Of course, subsequent neural processing could generate maps of ITD, but there is presently no clear evidence for this. Rather, it appears that ILD information is better aligned with visual maps in the superior colliculus [Schnupp and King, 1997], generating a population code that ultimately might be tightly linked to motor control (turning the head).

\section{Lizards}

This review has focused on neural coding strategies among several predatory species in order to determine if selective pressures for localization and accuracy lead to common solutions. To find out if other reptiles use similar solutions to those found in the archosaurs, we examined hearing in the Tokay gecko, an ambush predator. The use of hearing in hunting behavior is not known in the Tokay, but the smaller house gecko has been reported to intercept calling crickets and approach loudspeakers playing cricket calls [Sakaluk and Belwood, 1984]. Lizards also hear well, from $<1$ to $20 \mathrm{KHz}$, and a few, including geckos, are vocal [Marcellini, 1977; Marcellini et al., 1978; Wever, 1978; Tang et al., 2001; Manley and Köppl, 2008; Manley and Kraus, 2010]. The auditory brain stem circuits in lizards are organized in a similar fashion to birds and crocodilians, although not as well developed [Tang et al., 2012]. We have, however, found that geckos may use very different solutions to the problems of sound localization.

Lizard eardrums are coupled through their mouth, creating a pressure difference receiver [ChristensenDalsgaard and Manley, 2005, 2008; Vossen et al., 2010]. Recordings from the auditory nerve reveal highly directional responses (fig. 4). Auditory nerve responses are sensitive to both ITD and ILD, reflecting the acoustical interactions of direct and indirect sound components at the eardrum. Best ITD and click delays match interaural transmission delays, with a range of 200-500 $\mu$ s, and a mean of about $240 \mu$ s [Christensen-Dalsgaard et al., 2011]. Thus, sound sources from the same side as the ear 
drive the tympanum efficiently, while pressure from the moving air in the mouth cavity can act to suppress motion in the opposite tympanum. The output of the two coupled ears could provide an 'extreme' example of the meter- or slope-coding strategy (fig. 4). Of course, comparisons between the two ears are still needed to disambiguate other factors such as differentiating between a loud sound at a location that did not stimulate the ear well, and a quiet sound at an optimal location. Nevertheless, lizards with similar, homologous auditory brain stem circuits to those of the archosaurs appear to use a meter-coding strategy.

\section{Conclusion}

There are points of general interest that emerge from this discussion of ITD coding. First, the evolutionary issues discussed above show that parallel evolution might not always yield identical solutions. Birds and small mammals do not appear to have converged onto a unique, optimal solution, reinforcing observations from the stomatogastric system that multiple solutions can survive side by side even among individuals of the same species [Callaway and Marder, 2012], and examples from nudibranch swim control, which show closely related species can exhibit different behaviors despite homologous neural substrates [Newcomb and Katz, 2009]. Additionally, maps of auditory space are not necessary for sound localization, even in the barn owl, although the midbrain pathway may add speed to localization [Wagner, 1993]. Owls have a parallel pathway from the midbrain to the forebrain in which location is not mapped, but which can still guide localization because owls recover localization ability after lesions of the external nucleus. Localization is only irretrievably compromised when both forebrain and midbrain pathways are lesioned [Knudsen et al., 1993; Wagner, 1993].

Predators need speed and accuracy, and coordination of inputs from different sensory systems, but these come with a cost. An essential component of a predator-prey system such as the barn owl and its prey is the sensory performance of the prey. We have described the tuning of the predator's auditory system for increased spatial acuity, and there are other features that adapt the barn owl as an efficient predator of rodents, such as the structures of wing feathers producing a near silent flight, and the wellknown binocular and light-sensitive visual system [Wagner et al., 2013].

It is relevant to address whether the prey has any chances against such a formidable predator. Sensory sys- tems that could be beneficial for the prey would be vision (the silhouette of the approaching owl against the night sky), low-frequency hearing (wing beats) and motion detection (air currents generated by the wings) by the whiskers. An interesting study simulating prey escape behavior has been undertaken with barn owls [Shifferman and Eilam, 2004]. In this study, a dead prey item was pulled away when the owl had started its approach. Movement directions lateral to the owl's approach path decreased the owl's success rate to zero, and, in general, the success rate approaching moving prey was much less $(21 \%)$ than for stationary prey.

Thus, fast processing of the sensory cues generated by the approaching owl might be essential for the rodent. Air flow detected by the whiskers could contribute to a lastditch escape response. Also, even though special adaptations of the wings and feathers of barn owls reduce flight noise, the reduction is mostly at frequencies above $2 \mathrm{kHz}$. At lower frequencies, the sound emission (in the order of $20 \mathrm{~dB}$ SPL at $1 \mathrm{~m}$ distance) might be audible, and this might be a factor improving low-frequency hearing in certain small rodents, and the localization of these lowfrequency noises to facilitate escape response at right angles to the owl's trajectory. Since localization of low frequencies would be based on temporal cues in the small rodents, this predator-prey system pits maps against meters in the most concrete and direct fashion.

\section{Acknowledgments}

We thank Grace Capshaw, Katie Willis and the editors for helpful comments. This work was sponsored by NIH DC00436 to C.E.C., NIH P30 DC04664 to the University of Maryland Center for the Comparative and Evolutionary Biology of Hearing and by grants from the Danish Natural Science Research Council to J.C.D.

\footnotetext{
References Ashida G, Carr CE (2011): Sound localization: Jeffress and beyond. Curr Opin Neurobiol 21: 745-751.

Bala AD, Takahashi TT (2000): Pupillary dilation response as an indicator of auditory discrimination in the barn owl. J Comp Physiol A 186: 425-434.

Bala ADS, Spitzer MW, Takahashi TT (2003): Prediction of auditory spatial acuity from neural images on the owl's auditory space map. Nature 424:771-774.

Batra R, Yin TCT (2004): Cross correlation by neurons of the medial superior olive: a reexamination. J Assoc Res Otolaryngol 5:238252
} 
Beach FA (1944): Responses of captive alligators to auditory stimulation. Am Nat 78:481-505.

-Bierman HS, Carr CE (2015): Sound localization in the alligator. Hear Res DOI: 10.1016/j. heares.2015.05.009.

-Bierman HS, Thornton JL, Jones HG, Koka K, Young BA, Brandt C, Christensen-Dalsgaard J, Carr CE, Tollin DJ (2014): Biophysics of directional hearing in the American alligator (Alligator mississippiensis). J Exp Biol 217: 1094-1107.

Bremen P, Joris PX (2013): Axonal recordings from medial superior olive neurons obtained from the lateral lemniscus of the chinchilla (Chinchilla laniger). J Neurosci 33:1750617518.

Bunn DS, Warburton AB, Wilson RD (1982): The Barn Owl. London, Black.

Butts DA, Goldman MS (2006): Tuning curves, neuronal variability, and sensory coding. PLoS Biol 4:e92.

-Calford M, Piddington R (1988): Avian interaural canal enhances interaural delay. J Comp Physiol A 162:503-510.

Callaway EM, Marder E (2012): Common features of diverse circuits. Curr Opin Neurobiol 22:565-567.

-Carr CE, Konishi M (1988): Axonal delay lines for time measurement in the owl's brainstem. Proc Natl Acad Sci USA 85:8311-8315.

- Carr CE, Konishi M (1990): A circuit for detection of interaural time differences in the brain stem of the barn owl. J Neurosci 10:32273246.

- Carr CE, Soares D (2002): Evolutionary convergence and shared computational principles in the auditory system. Brain Behav Evol 59: 294-311.

-Carr CE, Soares D, Smolders J, Simon JZ (2009): Detection of interaural time differences in the alligator. J Neurosci 29:7978-7990.

- Carr CE, Shah S, McColgan T, Ashida G, Kuokkanen PT, Brill S, Kempter R, Wagner H (2015): Maps of interaural delay in the owl's nucleus laminaris. J Neurophysiol DOI: 10.1152/jn.00644.2015.

Christensen CB, Christensen-Dalsgaard J, Madsen PT (2015): Hearing of the African lungfish (Protopterus annectens) suggests underwater pressure detection and rudimentary aerial hearing in early tetrapods. J Exp Biol 218:381-387.

Christensen-Dalsgaard J, Carr CE (2008): Evolution of a sensory novelty: tympanic ears and the associated neural processing. Br Res Bull 75:365-370.

Christensen-Dalsgaard J, Manley GA (2005): Directionality of the lizard ear. J Exp Zool 208: 1209-1217.

-Christensen-Dalsgaard J, Manley GA (2008): Acoustical coupling of lizard eardrums. J Assoc Res Otolaryngol 9:407-416.

-Christensen-Dalsgaard J, Manley GA (2013): The malleable middle ear: an underappreciated player in the evolution of hearing in vertebrates; in Köppl C, Manley GA, Popper AN, Fay RR (eds): Insights from Comparative
Hearing Research. Springer Handbook of Auditory Research. New York, Springer, pp 157191.

Christensen-Dalsgaard J, Tang Y, Carr CE (2011): Binaural processing by the gecko auditory periphery. J Neurophysiol 105:1992-2004.

Clack JA (2011): Gaining Ground: The Origin and Evolution of Tetrapods. Bloomington, Indiana University Press.

Cohen YE, Knudsen EI (1999): Maps versus clusters: different representations of auditory space in the midbrain and forebrain. Trends Neurosci 22:128-135.

Dinets V (2013): Underwater sound locating capability in the American alligator (Alligator mississippiensis). J Herpetol 47:521-523.

Dufeau D (2011): The Evolution of Cranial Pneumaticity in Archosauria: Patterns of Paratympanic Sinus Development; PhD thesis, University of Ohio.

du Lac S, Knudsen EI (1990): Neural maps of head movement vector and speed in the optic tectum of the barn owl. J Neurophysiol 63:131-146.

-Fischer BJ, Pena JL (2009): Bilateral matching of frequency tuning in neural cross-correlators of the owl. Biol Cybern 100:521-531.

-Franken TP, Roberts MT, Wei L, Golding NL, Joris PX (2015): In vivo coincidence detection in mammalian sound localization generates phase delays. Nature 18:444-452.

Goodman DFM, Benichoux V, Brette R (2013): Decoding neural responses to temporal cues for sound localization. Elife 2:e01312.

-Görlich A, Illy M, Friauf E, Wagner H, Luksch H, Löhrke S (2010): Development of the delay lines in the nucleus laminaris of the chicken embryo revealed by optical imaging. Neuroscience 168:564-572.

Grothe B, Carr CE, Casseday J, Fritzsch B, Köppl C (2004): The evolution of central pathways and their neural processing patterns; in Manley GA, Fay RR (eds): Evolution of the Vertebrate Auditory System. Springer Handbook of Auditory Research. New York, Springer, pp 289-359.

Grothe B, Pecka M (2014): The natural history of sound localization in mammals - a story of neuronal inhibition. Front Neural Circuits 8: 116.

Grothe B, Pecka M, McAlpine D (2010): Mechanisms of sound localization in mammals. Physiol Rev 90:983-1012.

-Harper NS, McAlpine D (2004): Optimal neural population coding of an auditory spatial cue. Nature 430:682-686.

- Harper NS, Scott BH, Semple MN, McAlpine D (2014): The neural code for auditory space depends on sound frequency and head size in an optimal manner. PLoS One 9:e108154.

Heffner RS, Heffner HE (1992): Evolution of sound localization in mammals; in Webster DB, Popper AN, Fay RR (eds): The Evolutionary Biology of Hearing. New York, Springer, pp 691-715.

Higgs DM, Brittan-Powell EF, Soares D, Souza MJ, Carr CE, Dooling RJ, Popper AN (2002): Amphibious auditory responses of the Amer- ican alligator (Alligator mississipiensis). J Comp Physiol A Neuroethol Sens Neural Behav Physiol 188:217-223.

Hyson RL, Overholt EM, Lippe WR (1994): Cochlear microphonic measurements of interaural time differences in the chick. Hear Res 81:109-118.

Joris PX, Carney LH, Smith PH, Yin TCT (1994): Enhancement of neural synchronization in the anteroventral cochlear nucleus. I. Responses to tones at the characteristic frequency. J Neurophysiol 71:1022-1036.

-Joris PX, Yin TCT (1995): Envelope coding in the lateral superior olive. I. Sensitivity to interaural time differences. J Neurophysiol 73:10431062.

Klump GM (2000): Sound localization in birds; in Dooling RJ, Fay RR (eds): Comparative Hearing: Birds and Reptiles. Springer Handbook of Auditory Research. New York, Springer, pp 249-307.

Knudsen EI (1982): Auditory and Visual Maps of Space in the Optic Tectum of the Owl. J Neurosci 9:1177-1194.

Knudsen EI (2002): Instructed learning in the auditory localization pathway of the barn owl. Nature 417:322-328.

Knudsen EI (2011): Control from below: the role of a midbrain network in spatial attention. Eur J Neurosci 33:1961-1972.

Knudsen EI, Blasdel GG, Konishi M (1979): Sound localization by the barn owl (Tyto alba) measured with the search coil technique. J Comp Physiol A 133:1-11.

Knudsen EI, Knudsen PF, Masino T (1993): Parallel pathways mediating both sound localization and gaze control in the forebrain and midbrain of the barn owl. J Neurosci 13:28372852.

Konishi M (1973): How the owl tracks its prey: experiments with trained barn owls reveal how their acute sense of hearing enables them to catch prey in the dark. Am Sci 61: 414-424.

Köppl C (1997): Phase locking to high frequencies in the auditory nerve and cochlear nucleus magnocellularis of the barn owl, Tyto alba. J Neurosci 17:3312-3321.

Köppl C, Carr CE (2008): Maps of interaural time difference in the chicken's brainstem nucleus laminaris. Biol Cybern 98:541-559.

Kubke MF, Carr CE (2006): Morphological variation in the nucleus laminaris of birds. Int J Comp Psychol 19:83-97.

Kubke MF, Massoglia D, Carr CE (2004): Bigger brains or bigger nuclei? Regulating the size of auditory structures in birds. Brain Behav Evol 63:169-180.

Kundrát M, Janáček J (2007): Cranial pneumatization and auditory perceptions of the oviraptorid dinosaur Conchoraptor gracilis (Theropoda, Maniraptora) from the Late Cretaceous of Mongolia. Naturwissenschaften 94:769778 .

Laughlin SB (2001): Energy as a constraint on the coding and processing of sensory information. Curr Opin Neurobiol 11:475-480. 
Lee J, Groh JM (2014): Different stimuli, different spatial codes: a visual map and an auditory rate code for oculomotor space in the primate superior colliculus. PLoS One 9:e85017.

Lombard RE, Sumida SS (1992): Recent progress in understanding early tetrapods. Am Zool 32:609-622.

-MacLeod KM, Soares D, Carr CE (2006): Interaural timing difference circuits in the auditory brainstem of the emu (Dromaius novaehollandiae). J Comp Neurol 495:185-201.

Manley GA (2010): An evolutionary perspective on middle ears. Hear Res 263:3-8.

Manley GA (2012): Evolutionary paths to mammalian cochleae. J Assoc Res Otolaryngol 13: 733-743.

Manley GA, Köppl C (2008): What have lizard ears taught us about auditory physiology? Hear Res 238:3-11.

Manley GA, Kraus JEM (2010): Exceptional highfrequency hearing and matched vocalizations in Australian pygopod geckos. J Exp Biol 213: 1876-1885.

Marcellini D (1977): Acoustic and visual display behavior of gekkonid lizards. Integr Comp Biol 17:251-260.

Marcellini DL, Greenberg N, MacLean PD (1978): The acoustic behavior of lizards; in Greenberg N, MacLean PD (eds): Behavior and Neurology of Lizards. Rockville, US Department of Health, Education and Welfare, pp 287-300.

-McAlpine D, Jiang D, Palmer AR (2001): A neural code for low-frequency sound localization in mammals. Nat Neurosci 4:396-401.

-McColgan T, Shah S, Köppl C, Carr CE, Wagner $\mathrm{H}$ (2014): A functional circuit model of interaural time difference processing. J Neurophysiol 112:2850-2864.

-Michelsen A, Larsen O (2008): Pressure difference receiving ears. Bioinspir Biomim 3: 11001.

Modesto SP, Anderson JS (2004): The phylogenetic definition of reptilia. Syst Biol 53:815821.

Moiseff A (1989): Binaural disparity cues available to the barn owl for sound localization. J Comp Physiol A 164:629-636.

- Myoga MH, Lehnert S, Leibold C, Felmy F, Grothe B (2014): Glycinergic inhibition tunes coincidence detection in the auditory brainstem. Nat Commun 5:3790.

Mysore SP, Knudsen EI (2011): The role of a midbrain network in competitive stimulus selection. Curr Opin Neurobiol 21:653-660.

Newcomb JM, Katz PS (2009): Different functions for homologous serotonergic interneurons and serotonin in species-specific rhythmic behaviours. Proc Biol Sci 276:99-108.
Overholt EM, Rubel EW, Hyson RL (1992): A circuit for coding interaural time differences in the chick brainstem. J Neurosci 12:16981708.

Parks TN, Rubel EW (1978): Organization and development of the brain stem auditory nuclei of the chicken: primary afferent projections. J Comp Neurol 180:439-448.

Pecka M, Brand A, Behrend O, Grothe B (2008): Interaural time difference processing in the mammalian medial superior olive: the role of glycinergic inhibition. J Neurosci 28:69146925.

Rice W (1982): Acoustical location of prey by the marsh hawk: adaptation to concealed prey. The Auk 99:403-413.

Rubel EW, Smith D, Miller LM (1976): Organization and development of brain stem auditory nuclei of the chicken: ontogeny of $n$. magnocellularis and n. laminaris. J Comp Neurol 166:469-489.

Sakaluk SK, Belwood JJ (1984): Gecko phonotaxis to cricket calling song: a case of satellite predation. Anim Behav 32:659-662.

Schnupp JWH, Carr CE (2009): On hearing with more than one ear: lessons from evolution. Nat Neurosci 12:692-697.

Schnupp JWH, King AJ (1997): Coding for auditory space in the nucleus of the brachium of the inferior colliculus in the ferret. J Neurophysiol 78:2717-2731

Seidl AH, Rubel EW, Barría A (2014): Differential conduction velocity regulation in ipsilateral and contralateral collaterals innervating brainstem coincidence detector neurons. J Neurosci 34:4914-4919.

Shackleton T, Skottun B, Arnott RH, Palmer A (2003): Interaural time difference discrimination thresholds for single neurons in the inferior colliculus of guinea pigs. J Neurosci 23: 716.

Shifferman E, Eilam D (2004): Movement and direction of movement of a simulated prey affect the success rate in barn owl Tyto alba attack. J Avian Biol 35:111-116.

Sridharan D, Schwarz JS, Knudsen EI (2014): Selective attention in birds. Curr Biol 24:R510R513.

Takahashi TT, Bala ADS, Spitzer MW, Euston DR, Spezio ML, Keller CH (2003): The synthesis and use of the owl's auditory space map. Biol Cybern 89:378-387.

Takahashi TT, Carr CE, Brecha N, Konishi M (1987): Calcium binding protein-like immunoreactivity labels the terminal field of nucleus laminaris of the barn owl. J Neurosci 7: 1843-1856.
Takahashi TT, Konishi M (1988): Projections of the cochlear nuclei and nucleus laminaris to the inferior colliculus of the barn owl. J Comp Neurol 274:190-211.

Tang Y-Z, Zhuang L, Wang Z, McEachran J (2001): Advertisement calls and their relation to reproductive cycles in Gekko gecko (Reptilia, Lacertilia). Copeia 2001:248-253.

Tang Y, Christensen-Dalsgaard J, Carr CE (2012): Organization of the auditory brainstem in a lizard, Gekko gecko. I. Auditory nerve, cochlear nuclei, and superior olivary nuclei. J Comp Neurol 520:1784-1799.

Vergne A, Pritz MB, Mathevon N (2009): Acoustic communication in crocodilians: from behaviour to brain. Biol Rev 84:391-411.

-Volman SF (1990): Neuroethological approaches to the evolution of neural systems. Brain Behav Evol 36:154-165.

-Volman SF, Konishi M (1990): Comparative physiology of sound localization in four species of owls. Brain Behav Evol 36:196-215.

von Campenhausen M, Wagner H (2006): Influence of the facial ruff on the sound-receiving characteristics of the barn owl's ears. J Comp Physiol A Neuroethol Sens Neural Behav Physiol 192:1073-1082.

-Vossen C, Christensen-Dalsgaard J, van Hemmen JL (2010): Analytical model of internally coupled ears. J Acoust Soc Am 128:909-918.

Wagner H (1993): Sound-localization deficits induced by lesions in the barn owl's auditory space map. J Neurosci 13:371-386.

Wagner H, Kettler L, Orlowski J, Tellers P (2013): Neuroethology of prey capture in the barn owl (Tyto alba L.). J Physiol Paris 107:51-61.

Wagner H, Takahashi T, Konishi M (1987): Representation of interaural time difference in the central nucleus of the barn owl's inferior colliculus. J Neurosci 7:3105-3116.

Wever EG (1978): The Reptile Ear: Its Structure and Function. Princeton, Princeton University Press.

Witmer LM, Ridgely RC (2009): New insights into the brain, braincase, and ear region of tyrannosaurs (Dinosauria, Theropoda), with implications for sensory organization and behavior. Anat Rec (Hoboken) 292:1266-1296.

Woodward AR, White JH, Linda SB (1995): Maximum size of the alligator (Alligator mississippiensis). J Herpetol 29:507-513.

Young BA, Mathevon N, Tang Y (2014): Reptile Auditory Neuroethology: What Do Reptiles Do with Their Hearing?; in Köppl C, Manley GA, Popper AN, Fay RR (eds): Insights from Comparative Hearing Research. Springer Handbook of Auditory Research. New York, Springer, pp 323-346. 